\title{
A Study on the Pricing Model for 3PL of Inventory Financing
}

\author{
Zhilan Song, Huan Huang, Wenxue Ran, and Sen Liu \\ School of Logistics, Yunnan University of Finance and Economics, Kunming 650221, China \\ Correspondence should be addressed to Sen Liu; liusencool@gmail.com
}

Received 2 February 2016; Accepted 8 June 2016

Academic Editor: Cengiz Çinar

Copyright (C) 2016 Zhilan Song et al. This is an open access article distributed under the Creative Commons Attribution License, which permits unrestricted use, distribution, and reproduction in any medium, provided the original work is properly cited.

\begin{abstract}
Being a new research area, logistics finance solves the contradiction between banks and SMEs (small and medium enterprises) about financing; it is beneficial to financial market and logistics market development too. As a service innovation, it unites the interests of bank, 3PL (third-party logistics) providers, and SMEs and integrates material, finance, and information. Logistics finance has been developed in recent years in China, but the research is not enough on 3PL enterprises. On the background of that, the paper makes a research in the field of logistics finance with different pricing methods, based on the perspective of third-party logistics enterprises. This paper proposes a pricing model of inventory financing that can maximize the cash flow of 3PL enterprise, when the default rate of the small- and medium-sized enterprise is affected by the pledge price. And then this paper studies the model of inventory financing that can maximize the cash flow of enterprise under the condition of the existence of cash discount rate. The core factors affecting the loan-to-value ratio were established through analysis of mathematical model. We also consider the loan-to-value ratio of cash discount rate in the model. Results show that in the pledge of the known function and cash discount the price change can be calculated to meet enterprise cash flow lending rates and get biggest loan-to-value ratio.
\end{abstract}

\section{Introduction}

At present, due to small- and medium-sized enterprises smaller scale in China, bank credit rating is low in accordance with bank mortgage lack of fixed assets and the risk control system is not perfect and so on, making them difficultly get bank financing, and the lack of funds is seriously restricting the development of small- and medium-sized enterprises. However, based on the 3PL inventory financing business can better play a role in the advantages of the supply chain for the new approach of the financing of the small- and medium-sized enterprises; it can effectively solve the financing difficult problem in small- and medium-sized enterprise. By participating in inventory financing business, the banks and the 3PL enterprise can get the new customer resources, broaden the profit way of the enterprises, and can obtain the effect of altogether wins. Because of the features of 3PL enterprise business, it is fully grasping the information of the pledge market supply and demand and the pledge of price fluctuations that can be helpful to the banks to eliminate the risk of inventory financing business caused by the information asymmetry.
Inventory financing refers to the enterprise which needs financing (debit), in order for business activities to obtain loans, provide the pledge of fixed value to the enterprise (financial institution) that provides financial capital, and transfer the pledge to the 3PL enterprise (mediator) which has the qualification of legal custody of the inventory. This is the $3 \mathrm{PL}$ enterprise participating in the movables mortgage business.

Domestic and foreign experts are mainly from two perspectives on the basis of the 3PL enterprise to participate in the inventory pledge financing research.

(1) Research on the Inventory Financing Model. Lee and Rhee [1] put forward four extensively discussed coordination mechanisms for investigation. They show that positive financing costs call for trade credit in order to subsidize the retailer's costs of inventory financing. Using trade credit in addition to the contracts, the supplier fully coordinates the supply chain for the largest joint profits. Lacroix and Varnangis [2] stated that, through the comparison of the development of the logistics finance in the developed countries such as Europe and the United States, the innovation and integration 
of logistics and finance are of great significance to the developing countries in transition, to put forward specific proposals for developing countries to promote the logistics finance. Li et al. [3] analyzed the basic structure and content of logistics financial business and study on operational decision making and risk control decision making under capital constraints. Hofmann [4] studied the qualitative analysis of the importance of inventory financing from the perspective of logistics service providers.

Chan et al. [5] explained how mortgage finance interacts with public policy, particularly tax policy, to influence a household's decision of owning or renting. Sun et al. [6] discuss the effect of inventory financing on the performance of node enterprises. They also examine the supply chain composed of one supplier and one capital-constrained retailer according to the supply chain inventory financing business operation process. Wang [7] based on loan-to-value ratio as the research object, taking the method of model building, builds the loan-to-value ratio model under the different modes of pledge and makes an important reference for the bank handling inventory financing business to small- and medium-sized enterprises and deciding the optimal loan-tovalue ratio, which is of important practical and theoretical significance.

Wonglimpiyarat [8] is mainly concerned with the bank financing policies to support SME development in China. The study provides lessons and policy guidelines to improve the competitiveness of SMEs in China. Luo et al. [9] consider small- and medium-sized enterprise (SME) with a funding gap intending to invest in a project, of which the cash flow follows a double exponential jump-diffusion process. In contrast to traditional corporate finance theory, they assume the SME is unable to get a loan directly from a bank and hence it enters into a partial guarantee agreement with an insurer and a lender.

(2) Research on Financing Pricing Model. Buzacott and Zhang [10] analyzed the existence of fixed mortgage financing business inventory management. They integrated the mortgage financing into the enterprise's production decision making, studied how to determine the loan interest rate and the loanto-value ratios in the fixed inventory financing business, and analyzed the changes of the two parties in the inventory financing business. Soni and Joshi [11] proposed a generalized economic order quantity- (EOQ-) based inventory model and financing pricing model using a trade credit policy in a fuzzy sense. Yang [12] studied capital market imperfections into a structure framework of inventory investments and investigated impacts of trade credit on firms' inventory dynamics and analyzed the relationship between trade credit and bank loans.

Zhang and Zhao [13] studied that the pledge of inventory demand is stochastic volatility and how the bank determines the loan-to-value ratios and different risk preferences of banks charge rate of selection. Chen et al. [14] set up a risk model for measuring the value of inventory financing, through the sensitivity analysis method to analyze the related factors in the model, and the biggest risk factors were obtained. Hwan Lee and Rhee [15] considered the inventory financing cost effect on the coordination of supply chain in three (buyback, quantity discounts, and tow-shift system) factors. Srinivasa Raghavan and Mishra [16] investigate lender's problem of financing both the firms by making a joint decision on the loan amount and comparing it with the case when lender makes independent decision on loan amount for both the firms.

In Meng's study [17], the pricing strategy of nonloan financing model is enriched and developed, and effective means are provided to solve the financing pricing with dualcore variables, which is helpful to guide the rational allocation of profit margin between borrower and lender and promotes the stable and healthy development of MCA ecosystem. Kim et al. [18] explore a variety of effects of external financing, which is in the case of Korea ITM, for example. This study is building up the prior literature primarily devoted to an effect of internal financing on TIA of firms. Zhang and Chen [19] discussed, under the supply chain finance environment in China, the bank's financial pricing strategies of accounts receivable. Then they put forward some suggestions on the supply chain finance environment bases on the analysis of the whole paper.

Although there is a lot of research around the world, providing a certain theoretical basis for the smooth development of inventory pledge business, most of the research is biased in favor of the logistics financing business model research and the bank based research, ignoring the third-party logistics enterprises in inventory financing related issues, such as loan-to-value ratios, loan period, and default rate of loan companies. In this paper, we study the problem of loan-tovalue ratios in the inventory financing business under the $3 \mathrm{PL}$ enterprises. Taking full account of the loan-to-value ratios is closely related to factors; in practice, the 3PL enterprises rely on the experience of the valuation of the loan-to-value ratios, by building models, determining the 3PL enterprises in inventory financing and the maximum cash flow loan-tovalue ratios, to ensure that the 3PL enterprise gains maximum profits.

\section{Model Description}

2.1. Risk Factors in Inventory Pledge. Controllable risk, also known as the systemic risk, refers to the risks caused by improper operation, stealing, breach of contract, and so on in 3PL enterprises and financing enterprises. And the risk is called controllable risk, also known as unsystematic risk. This kind of risk and the entire logistics financial market have no systematic connection, but it can be through the establishment of strict inventory operation procedures, strict inventory control system and strict credit review procedures, and other means to reduce the controllable risk. Controllable risk mainly includes three aspects: 3PL enterprise's supervision risk, credit risk, and legal risk [20].

(1) Regulatory Risks. Regulatory risks mainly include inventory risk, transportation risk, fire risk, and information system risk. Inventory risk refers to the risk of inventory reduction due to improper management of the warehouse and the risk of inventory reduction due to poor management. 
The fire risk refers to the risk of inventory loss caused by the failure of the fire equipment and transportation risk. Information system risk is defined as the risk of information system failure, such as virus damage, sensor failure, human error, and other causes of the pledge. According to the regulatory risk process, which can be classified as the risk of storage, in order to facilitate the subsequent modeling, these risks are uniformly referred to as "warehouse risk" in this paper for convenience.

(2) Credit Risk. Credit risk refers to the risk of loss caused by the party logistics enterprises in the process of inventory pledge because the loan companies did not use the contract to fulfill the obligations of the 3PL enterprises, mainly affected by capacity, enterprise debt service capacity, and enterprise profitability. In this paper, because the credit level of small and medium enterprises is relatively low and the possibility of default is relatively high, we assume that the default rate of the loan companies will be affected by the value of collateral.

(3) Legal Risk. The legal risks of pledge mainly include the risk of the property right and the authenticity of the pledge, including whether the pledger has the legal ownership of the pledge, whether there are flaws in the pledge, whether the goods have been pledged or supervised by the third party, and whether the pledge was seized or seizure. In this paper, we would not consider the legal risk in order to calculate conveniently.

There is a risk that is not controlled by banks, logistics enterprises, and financing enterprises, which is not controllable risk, also known as systemic risk. Such risks exist in the macroenvironment, no matter how the enterprise management will always exist, such as accident risk, natural disaster risk, and economic environment risk. Uncontrolled risk will lead to the whole economic and social unrest; people can not take a risk in advance of this risk to avoid or use targeted measures. In the research of this paper, the impact of the risk on the pricing of pledge is ignored. Therefore, the system risk also is not considered in this paper.

2.2. The Factors of Loan-to-Value Ratios in Inventory Business. Loan-to-value ratio refers to the 3PL enterprises in the business of inventory financing provided by the loan amount and the ratio of initial assessment of value of the pledge. Loan-tovalues ratios as the core of factors in the inventory financing business not only affect the expected return of third-party logistics enterprise, but also affect the 3PL enterprises risk control level. The main factors that affect the stock pledge rate are as follows.

(1) Fluctuations in the Price of the Pledge. The 3PL enterprises in the inventory pledge to participate in the business will take full account of the value of the pledge of inventory changes. If enterprises are expected to expire at the end of term, the pledge of high prices will provide higher loan-to-value ratios; if the enterprise is expected to expire at the end of term, the pledge of price variance is bigger and will provide lower loanto-value ratios. Because when the final price of the collateral is expected to be higher, if the breach is by small- and mediumsized enterprises, the 3PL enterprises suffered losses will be relatively small, at this time the 3PL enterprises choose a high loan-to-value ratios, to provide more loans for small and medium enterprises to get more income; on the contrary, the 3PL enterprises predict that the risk of loss is higher, and they will set lower loan-to-value ratios, in order to reduce the risk of loss.

(2) Pledge Loan Period. In inventory financing business, loan time is short; so, the small and medium enterprises are under high repayment pressure and in the short term, changes in the value of the inventory risk are also small; small- and mediumsized enterprises have lower risk of default. So for a certain value of inventory pledge, borrowing short term will improve the loan-to-value ratios and the 3PL enterprise to provide more loans to small- and medium-sized enterprises, to obtain greater benefits. On the contrary, the 3PL enterprises will reduce loan-to-value ratios.

(3) Risk Preference of the 3PL Enterprises. The 3PL enterprises in determining inventory loan-to-value ratios, considering their own expected return maximization, also need to consider the financing business of the controllable risk level. In order to avoid suffering a greater loss, 3PL enterprises tend to choose lower loan-to-value ratios and reduce the loans when they are risk averse. To the contrary, 3PL enterprises tend to choose higher loan-to-value ratios and increase the loans to get the high-yield when they are risk loving.

\section{The Proposed Method}

Currently there are mainly four types of inventory financing: receipt pledge business, trust business supervision, unified credit business, and logistics bank business. Under the unified credit business model, this paper focuses on the discussion of the 3PL enterprise's expected return and the optimal inventory loan-to-value ratios and so forth.

Unified credit financing business model is a kind of movable property mortgage credit business, which is different from the traditional movable property mortgage credit business. During inventory pledge, the pledge's actual ownership belongs to the pledgee and its allocation of regulatory power belongs to the supervisor. That is to say, the inventory's actual ownership belongs to the financial institution and its allocation of regulatory power belongs to the 3PL. During the period of pledge, when the pledge value is more than the contract minimum value (maximum value), financing companies more than the minimum value (highest value) can be partly free to deposit or withdraw; if the financing enterprises have production needs, they can replace the original pledge by prearranged methods. When the financing time limit is over, after these small and medium enterprises carry out their obligations under the provisions of pledge contract, the pledge's ownership will be transferred to pledger. In the process of financing, the 3PL enterprises take inventory security guarantees. 
3.1. Model Basic Assumptions and Variables. Taking the $3 \mathrm{PL}$ enterprises as the research subject, there are two main research areas in the field of inventory pledge financing, the study of endogenous variable and the external variable of default. At the end of the inventory financing, the financing enterprise can return the loan to the real value of the goods and also depend on the credit; therefore, the inventory financing strategy is based on the external conditions to choose the right collateral rate and loan-to-value ratios. In order to reduce unnecessary computation, the model is as follows:

(1) The 3PL enterprise's logistics warehousing expense ratio has nothing to do with the value of the pledge; it is the $3 \mathrm{PL}$ enterprise's expense.

(2) The deposit rate is compounded.

(3) There is no systemic risk in the inventory financing.

(4) It is without considering the national tax.

(5) Inventory financing business is short term (within a year) financing business; it is assumed that the loan interest rate is unchanged during the period of the pledge.

Assuming that the final value of the pledge of the enterprise during the period of the loan is $Q_{T}$, obeying a single peak distribution function, the probability density function is $F(t)$, and $F(t) \geq 0$ continuous differentiable, $t \geq 0$; that is $Q_{T}=\int_{0}^{T} t f(t) d t$.

$T$ is the financing enterprise sales cycle (or repayment period), in units of years.

$i$ stands for loan-to-value ratios.

$R_{0}$ stands for the 3PL enterprises to pay financial institutions unified credit line of interest rates: $0<R_{0}<1$.

$r_{e}$ stands for 3PL enterprises to provide inventory financing interest rate: $R_{0}<r_{e} \leq 1$.

$p_{0}$ is the value of the initial pledge.

$v_{0}$ : the third-party logistics enterprises are willing to provide the financing amount of the loan enterprise, the maximum amount of financing, and the initial pledge value $p_{0}$ and the pledge rate $i$; that is, $v_{0}=p_{0} \cdot i$.

$v_{t}$ is the final value of the loan lent by the 3PL enterprises.

$S_{t}$ : it is the function of the sum of the principal and interest of financing enterprises at the end term. Hence, based on the value change of pledge, the final received principal and interest of 3PL enterprise are

$$
S_{t}=v_{0} \cdot\left(1+r_{e}\right)^{T}=i \cdot\left(1+r_{e}\right)^{T} \cdot p_{0} .
$$

$Q_{T}$ is final expected value of the pledge: $Q_{T}=\int_{0}^{T} t f(t) d t$, in units of yuan.

$\mu$ is the cash discount rate of the $3 \mathrm{PL}$ enterprise to provide loan enterprise.

$M$ is the probability of default of a loan enterprise $(0 \leq$ $M \leq 1)$.

$\omega$ is the rate of loan companies willing to bear the loss.

$h$ is warehouse cost related to the pledge value; the higher the value, the higher the cost of warehousing.
$C_{s}$ is warehouse cost of the $3 \mathrm{PL}$ enterprises: $C_{s}=\left(Q_{T} / 2\right)$. $h \cdot T$, in units of yuan.

$\chi_{t}^{0}:$ at the end of the term, when loan enterprise defaults, it is the 3PL enterprise's flow of cash.

$\chi_{t}^{1}$ : it is the cash flow of 3PL enterprises when financing enterprises carry out their pledge contract in the end term.

$E\left(\chi_{t}\right)$ is the third-party logistics enterprises' expected flow of cash in the end.

3.2. The Inventory Model of Cash Discount. The characteristic of this model is not considered a cash discount factor, and it is suitable for the financing enterprises which are not hedging in future market; the changes in the value of the inventory can bring big risks to finance (to establish a model of the process to provide a basic reference here temporarily not to consider the effects of other risk factors for financing). According to the above analysis, the main factor of the change of the value of the pledge is the main factor to establish the model as follows.

The final received capital and interest of $3 \mathrm{PL}$ enterprise is $S_{t}=V_{0} \cdot\left(1+r_{e}\right)^{T}=i \cdot\left(1+r_{e}\right)^{T} \cdot p_{0}$; assuming that enterprises are willing to bear the loss rate $\omega$, that is, $(1-\omega) Q_{t} \prec S_{t}$, enterprise will default; and enterprise default rate is $M=$ $\int_{0}^{S_{t} /(1-\omega)} f(t) d t$.

(1) When borrowing enterprise to fulfill the pledge contract, 3PL enterprise's flow of cash is

$$
\begin{aligned}
\chi_{t}^{1}= & S_{t}-v_{t}-C_{s}, \\
\chi_{t}^{1}= & i \cdot\left(1+r_{e}\right)^{T} \cdot p_{0}-i \cdot\left(1+R_{0}\right)^{T} \cdot p_{0} \\
& \quad-\frac{h \cdot T \int_{0}^{T} t f(t) d t}{2} .
\end{aligned}
$$

(2) When the borrower defaults, the 3PL enterprise's flow of cash is

$$
\begin{aligned}
\chi_{t}^{0}= & Q_{T}-v_{t}-C_{s}, \\
\chi_{t}^{0}= & \int_{0}^{T} t f(t) d t-i \cdot\left(1+R_{0}\right)^{T} \cdot p_{0} \\
& -\frac{h \cdot T \int_{0}^{T} t f(t) d t}{2} .
\end{aligned}
$$

The expected cash flow of the loan companies is

$$
\begin{aligned}
E\left(\chi_{t}\right)= & (1-M) \chi_{t}^{1}+M \chi_{t}^{0} \\
E\left(\chi_{t}\right)= & S_{t}+M\left(Q_{T}-S_{t}\right)-v_{t}-C_{s} \\
= & (1-M) \cdot S_{t}+M \cdot Q_{T}-i \cdot\left(1+R_{0}\right)^{T} \cdot p_{0} \\
& -\frac{h \cdot T \int_{0}^{T} t f(t) d t}{2} .
\end{aligned}
$$


Differentiating loan-to-value ratios on the function of cash flow in the 3PL enterprises, get the following results:

$$
\begin{aligned}
\frac{\partial E}{\partial i}= & -S_{t} \cdot \frac{\left(1+r_{e}\right)^{T} \cdot p_{0}}{1-\omega} \cdot f\left(\frac{S_{t}}{1-\omega}\right)+(1-M) \\
& \cdot\left(1+r_{e}\right)^{T} \cdot p_{0}+Q_{T} \cdot \frac{\left(1+r_{e}\right)^{T} \cdot p_{0}}{1-\omega} \\
& \cdot f\left(\frac{S_{t}}{1-\omega}\right)-p_{0} \cdot\left(1+R_{0}\right)^{T} .
\end{aligned}
$$

Simplification:

$$
\begin{aligned}
& \frac{\partial E}{\partial i}=p_{0}\left[\frac{\left(1+r_{e}\right)^{T}}{1-\omega} f\left(\frac{S_{t}}{1-\omega}\right)\left(Q_{T}-S_{t}\right)+(1-M)\right. \\
& \left.\cdot\left(1+r_{e}\right)^{T}-\left(1+R_{0}\right)^{T}\right], \\
& \frac{\partial E}{\partial i}=\frac{p_{0} \cdot\left(1+r_{e}\right)^{T}}{1-\omega}\left[\left(Q_{T}-S_{t}\right) f\left(\frac{S_{t}}{1-\omega}\right)+(1-\omega)\right. \\
& \left.\cdot(1-M)-(1-\omega)\left(\frac{1+R_{0}}{1+r_{e}}\right)^{T}\right] .
\end{aligned}
$$

Because of the assumption of the single peak symmetric density function, the maximum of $3 \mathrm{PL}$ enterprises expected cash flow is

$$
\begin{aligned}
& \left(Q_{T}-S_{t}\right) f\left(\frac{S_{t}}{1-\omega}\right)+(1-\omega) \cdot(1-M) \\
& -(1-\omega)\left(\frac{1+R_{0}}{1+r_{e}}\right)^{T}=0, \\
& \text { That } \frac{S_{t}}{1-\omega}=S \\
& \text { So: }\left(Q_{T}-S_{t}\right) f(S)+(1-\omega) \cdot(1-M) \\
& \quad-(1-\omega)\left(\frac{1+R_{0}}{1+r_{e}}\right)^{T}=0, \\
& M=1+\left(\frac{1+R_{0}}{1+r_{e}}\right)^{T}+\left(\frac{Q_{T}}{1-\omega}-S\right) f(S) .
\end{aligned}
$$

3.3. Pledge Model with Mash Discount. Borrowing enterprises in the accounts receivable may not be timely repayment but used in other ways; it will generate some of the other uncontrolled risks; in order to avoid the risk, the 3PL companies can consider joining the cash discount rate of this variable for motivation and timely repayment of financing enterprises.

Now assuming that the $3 \mathrm{PL}$ enterprises committed in $T_{1}, T_{2}, T_{3}$, the probability that the financing enterprise will choose to repay in the three time points is $\mu_{1}, \mu_{2}, \mu_{3},\left(\mu_{1}>\right.$ $\left.\mu_{2}>\mu_{3}\right)$. Finance companies will choose the probability of repayment at three time points which are $H_{T_{1}}, H_{T_{2}}, H_{T_{3}}$, and $H_{T_{1}}+H_{T_{2}}+H_{T_{3}}=1$.
The flow of cash of the 3PL enterprises at different time is as follows.

$T_{1}$ of the time: the cash flow of 3PL enterprises: $\xi_{1}=S_{t}-$ $\left(S_{t}-v_{0}\right)\left(1-\mu_{1}\right)-v_{t}-C_{s}$.

$T_{2}$ of the time: the cash flow of 3PL enterprises: $\xi_{2}=S_{t}-$ $\left(S_{t}-v_{0}\right)\left(1-\mu_{2}\right)-v_{t}-C_{s}$.

$T_{3}$ of the time: the cash flow of 3PL enterprises: $\xi_{3}=S_{t}-$ $\left(S_{t}-v_{0}\right)\left(1-\mu_{3}\right)-v_{t}-C_{s}$.

When loan companies do not fulfill the pledge contract, the cash flow of $3 \mathrm{PL}$ enterprises is as follows: $\xi_{4}=Q_{T}-v_{t}-C_{s}$.

The expected cash flow of the financing enterprises is $E_{1}(\xi)$ :

$$
\begin{aligned}
E_{1}(\xi)= & (1-M)\left(H_{T_{1}} \cdot \xi_{1}+H_{T_{2}} \cdot \xi_{2}+H_{T_{3}} \cdot \xi_{3}\right) \\
& +M \xi_{4} .
\end{aligned}
$$

That is,

$$
\begin{aligned}
& E_{1}(\xi)=(1-M) \\
& \quad \cdot\left[S_{T}\left(H_{T_{1}}\left(1-\mu_{1}\right)+H_{T_{2}}\left(1-\mu_{2}\right)+H_{T_{3}}\left(1-\mu_{3}\right)\right)\right. \\
& \left.\quad-v_{t}-C_{s}\right]+M\left(Q_{T}-v_{t}-C_{s}\right) .
\end{aligned}
$$

So,

$$
\begin{aligned}
E_{1}(\xi)= & (1-M)\left(A \cdot S_{t}-v_{t}-C_{s}\right) \\
& +M\left(Q_{T}-v_{t}-C_{s}\right) .
\end{aligned}
$$

Among them

$$
A=H_{T_{1}}\left(1-\mu_{1}\right)+H_{T_{2}}\left(1-\mu_{2}\right)+H_{T_{3}}\left(1-\mu_{3}\right) .
$$

Differentiating loan-to-value ratios on the function of cash flow in the 3PL enterprises, get the following results:

$$
\begin{aligned}
\frac{\partial E_{1}}{\partial i} & \\
= & -p_{0} \cdot\left(\frac{1+r_{e}}{1-\omega}\right) \cdot f\left(\frac{S_{t}}{1-\omega}\right)\left(Q_{T}-S_{t}\right)+(1-\omega) \\
& \cdot(1-M) \\
& -\left[H_{T_{1}}\left(1-\mu_{1}\right)+H_{T_{2}}\left(1-\mu_{2}\right)+H_{T_{3}}\left(1-\mu_{3}\right)\right] \\
& \cdot p_{0} \cdot\left(\frac{1+r_{e}}{1-\omega}\right) .
\end{aligned}
$$

Because of the assumption that $f(p)$ is a single peak symmetric density function, the $3 \mathrm{PL}$ enterprises have the expected maximum cash flow to meet

$$
\frac{\partial E_{1}}{\partial i}=0 .
$$

Finally

$$
M=1+\frac{f\left(S_{t} /(1-\omega)\right)\left(Q_{T}-A \cdot S_{t}\right)}{A(1-\omega)} .
$$




\section{Numerical Example}

4.1. Example. At the beginning, the market value of smalland medium-sized enterprise's inventory is 2.5 million, the loan is for 90 days, and according to the research, the value of inventory changes to meet $f(t)=\left(1 / \sqrt{2 \pi \cdot 6^{2}}\right) e^{-(t-260)^{2} /\left(2 \cdot 6^{2}\right)}$. The loss rate the small- and medium-sized enterprise can bear is $20 \%$ and the enterprise does not take any measures to the pledge for hedging in futures markets. According to the actual survey, the loan enterprise credit period is 60 days. The cash discount rate of the 3PL enterprise to provide loan enterprise is $\mu_{1}=2 / 20, \mu_{2}=1 / 45, \mu_{3}=n / 60$, and the probability of small and medium enterprise to return the loan ahead of schedule is $H_{T_{1}}=0.52, H_{T_{2}}=0.35, H_{T_{3}}=$ 0.13 . The warehousing cost of $3 \mathrm{PL}$ enterprise is $2 \%$ of pledge, and the 3PL enterprise provides inventory financing interest rate which is $7 \%$ and the $3 \mathrm{PL}$ enterprises pay to financial institutions unified credit line of interest rates which is $4 \%$.

The actual situation of the 3PL enterprises in (14) is

$$
\begin{aligned}
1 & -\int_{0}^{250 \cdot i \cdot\left(1+r_{e}\right.}{ }^{0.25} f(t) d t \\
& =0.9757 \cdot f\left(250 \cdot i \cdot\left(1+r_{e}\right)^{0.25}\right) .
\end{aligned}
$$

Let

$$
250 \cdot i \cdot\left(1+r_{e}\right)^{0.25}=Z .
$$

Then

$$
1-\int_{0}^{Z} f(t) d t=0.9757 \cdot f(Z) .
$$

Solving $Z$ :

$$
250 \cdot i \cdot\left(1+r_{e}\right)^{0.25}=0.788 .
$$

At last, we get the 3PL enterprise expected final maximum loan-to-value ratio of cash flow for $i=0.7326$. At this time of the $3 \mathrm{PL}$ enterprise expected cash flow is 24473.43 yuan.

4.2. Sensitivity Analysis. In order to see clearly how the variables influence the results, we make a sensitivity analysis in the end. In our paper, $i$ is the key variable, so we do a sensitivity analysis of $i$. In order to get a more accurate estimate, let us suppose that the percentage change is $2 \%$, so there are four different matching possibilities: $i=69.26 \%$, $i=71.26 \%, i=75.26 \%$, and $i=77.26 \%$. Then using (14) and (15) we can get four different expected cash flows of the 3PL enterprises: $E\left(x_{t}\right)=24761.25, E\left(x_{t}\right)=24696.58$, $E\left(x_{t}\right)=24312.37$, and $E\left(x_{t}\right)=24265.38$. From Table 1 we can see clearly that the result of $\Delta E\left(x_{t}\right) / \Delta i$ is negative number; that is to say, when $i=69.26 \%, i=71.26 \%, i=75.26 \%$, and $i=77.26 \%$, the expected cash flows of the 3PL enterprises are all lower than $i=0.7326$, so we concluded that $i=0.7326$ is the best inventory financing choice for 3PL enterprises.

\section{Conclusions}

In recent years, inventory financing, as an innovative financial instrument, has developed rapidly in China. It can help
TABLE 1: The sensitivity analysis of $i$.

\begin{tabular}{lccccc}
\hline $\begin{array}{l}\text { Percentage } \\
\text { changes }\end{array}$ & $-4.00 \%$ & $-2.00 \%$ & Based point & $2.00 \%$ & $4.00 \%$ \\
\hline$i$ & $69.26 \%$ & $71.26 \%$ & $73.26 \%$ & $75.26 \%$ & $77.26 \%$ \\
$E\left(x_{t}\right)$ & 24761.25 & 24696.58 & 24473.43 & 24312.37 & 24265.38 \\
$\Delta i$ & $-4.58 \%$ & $-2.73 \%$ & - & $2.73 \%$ & $5.17 \%$ \\
$\Delta E\left(x_{t}\right)$ & $1.18 \%$ & $0.91 \%$ & - & $-0.66 \%$ & $-0.85 \%$ \\
$\Delta E\left(x_{t}\right) / \Delta i$ & -0.26 & -0.33 & - & -0.24 & -0.16 \\
\hline
\end{tabular}

us solve the problem caused by the occupation of a large amount of circulating fund. The pattern of inventory financing coordinates the benefits between core enterprise, bank, and middle- and small-sized enterprises effectively. At the same time, the storage enterprise also profits a lot in the participation of cargo storage business.

This paper proposes two novel models to solve the problem of 3PL enterprises: how to get a maximum loanto-value ratio by different pricing methods. Firstly, we study that the 3PL enterprises participate in the inventory financing business. Secondly, we suppose the final value of smalland medium-sized enterprises is fit for normal probability function. Thirdly, this paper assumes that the default rate of small- and medium-sized enterprises related to the value of the pledge.

Moreover, we add the cash discount rate and other factors to establish the final of the 3PL enterprises pricing model. In the end, a case of 3PL enterprises study shows that when taking the loan interest rate of bank in short time and the risk compensation rate factors into consideration, we can get the optimum inventory financing cash flow best for 3PL enterprises from the two models in the paper. This paper can give 3PL enterprises some advice about how to take some measures of avoiding risks and how to get the optimal loanto-value ratio.

\section{Competing Interests}

The authors declare that there are no competing interests regarding the publication of this paper.

\section{Acknowledgments}

This research was supported by the National Natural Science Foundation Council of China under Project no. 71502159; the Applied Basic Research Science Foundation of Yunnan Provincial Department of Science and Technology under Project no. 2015FD028; the Science Foundation of Yunnan Provincial Department of Education under Project no. 2015Y269; and the Science and Technology Innovation Team Fund of Logistics Engineering in Colleges and Universities of Yunnan Province in China.

\section{References}

[1] C. H. Lee and B.-D. Rhee, "Coordination contracts in the presence of positive inventory financing costs," International 
Journal of Production Economics, vol. 124, no. 2, pp. 331-339, 2010.

[2] R. Lacroix and P. Varnangis, "Using warehouse receipts in developing and transition economies," Finance \& Development, no. 9, pp. 36-39, 1996

[3] Y.-X. Li, S.-Y. Wang, and G.-Z. Feng, "Practical development and theoretic review of logistics finance-a new discipline direction," System Engineering Theory \& Practice, vol. 30, no. 1, pp. 1-13, 2010.

[4] E. Hofmann, "Inventory financing in supply chains: a logistics service provider-approach," International Journal of Physical Distribution and Logistics Management, vol. 39, no. 9, pp. 716740, 2009.

[5] S. Chan, A. Haughwout, and J. Tracy, "How mortgage finance affects the urban landscape," in Handbook of Regional and Urban Economics, vol. 5, chapter 15, pp. 987-1045, Elsevier, 2015.

[6] X. Sun, G. Zhao, and Y. Wang, "Effect analysis on supply chain performance based on inventory pledging financing," Journal of Shenzhen University Science and Engineering, vol. 31, no. 3, pp. 317-324, 2014.

[7] Y. Wang, Research on the loan-to-value ratio model of inventory and inventory portfolio which based on the different modes of pledge [M.S. dissertation], Yunnan Normal University, Kunming, China, 2015.

[8] J. Wonglimpiyarat, "The new challenge of financing innovative economic growth through SME development in the People's Republic of China," Technology in Society, vol. 46, pp. 49-57, 2016.

[9] P. Luo, H. Wang, and Z. Yang, "Investment and financing for SMEs with a partial guarantee and jump risk," European Journal of Operational Research, vol. 249, no. 3, pp. 1161-1168, 2016.

[10] J. A. Buzacott and R. Q. Zhang, "Inventory management with asset-based financing," Management Science, vol. 50, no. 9, pp. 1274-1292, 2004.

[11] H. N. Soni and M. Joshi, "A fuzzy framework for coordinating pricing and inventory policies for deteriorating items under retailer partial trade credit financing," Computers and Industrial Engineering, vol. 66, no. 4, pp. 865-878, 2013.

[12] X. Yang, "Trade credit versus bank credit: evidence from corporate inventory financing," The Quarterly Review of Economics and Finance, vol. 51, no. 4, pp. 419-434, 2011.

[13] Q. Zhang and Q. Zhao, "A study on the decision of the loan-tovalue ratios of the pledge loan," Chinese Journal of Management Science, vol. 18, no. 5, pp. 21-27, 2010.

[14] B. Chen, G. Feng, and Y. Li, "The risk value measurement of inventory financing business," Journal of Systems Engineering, no. 10, pp. 21-26, 2007.

[15] C. Hwan Lee and B.-D. Rhee, "Coordination contracts in the presence of positive inventory financing costs," International Journal of Production Economics, vol. 124, no. 2, pp. 331-339, 2010.

[16] N. R. Srinivasa Raghavan and V. K. Mishra, "Short-term financing in a cash-constrained supply chain," International Journal of Production Economics, vol. 134, no. 2, pp. 407-412, 2011.

[17] Y. Meng, Research on pricing strategy of merchant cash advance financing [M.S. dissertation], Tianjin University of Technology, 2015.

[18] S. Kim, H. Lee, and J. Kim, "Divergent effects of external financing on technology innovation activity: Korean evidence," Technological Forecasting and Social Change, no. 106, pp. 22-30, 2016.
[19] B. Zhang and J. Chen, "Research on the the bank's financial princing strategies of accounts receivable in supply-chain finance environment. Study on the supply-chain finance environment in China, the bank's financial princing strategies of accounts receivable," Statistics \& Decision, no. 3, pp. 51-55, 2016.

[20] J. Guo, The Research on Logistics Finance Innovation Model and Risk Management from the View of TPL, South China University of Technology, Guangzhou, China, 2012. 


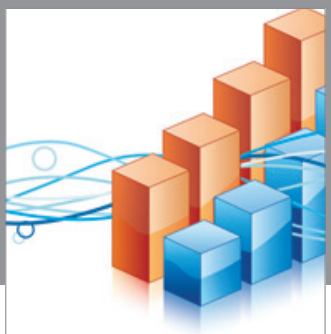

Advances in

Operations Research

vatem alat4

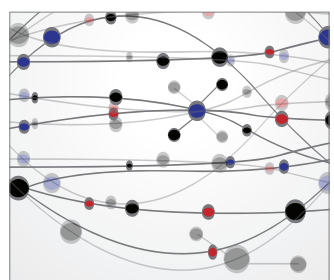

\section{The Scientific} World Journal
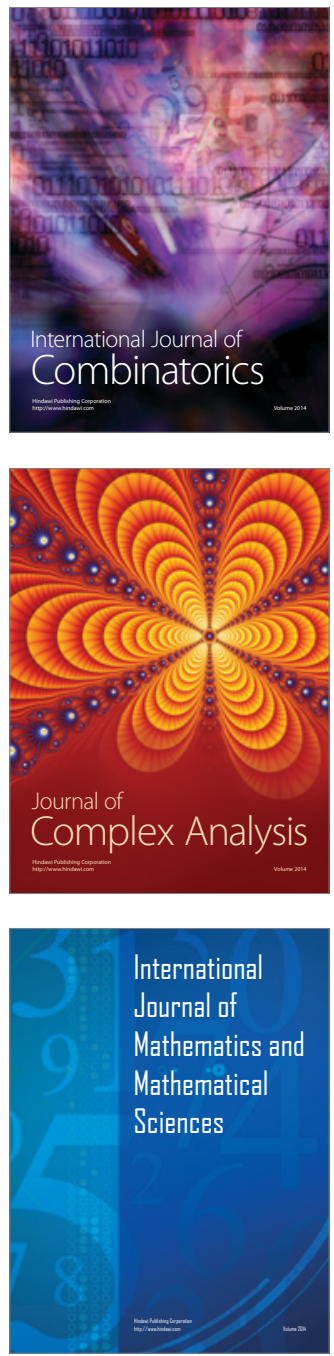
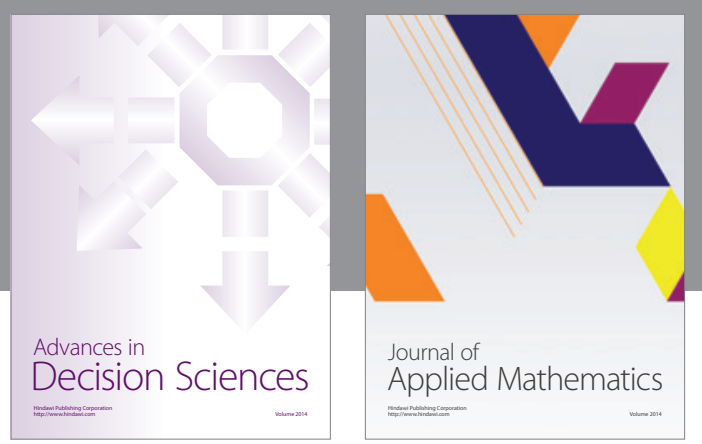

Algebra

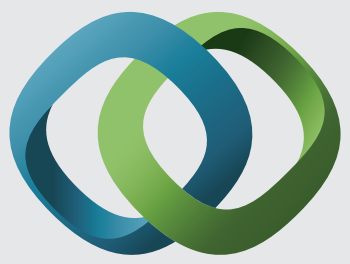

\section{Hindawi}

Submit your manuscripts at

http://www.hindawi.com
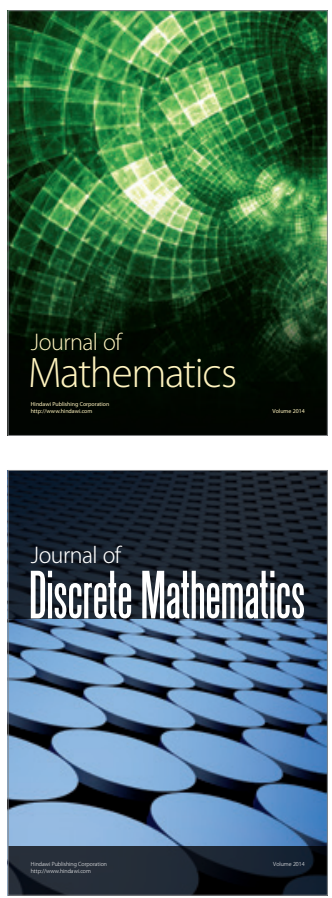

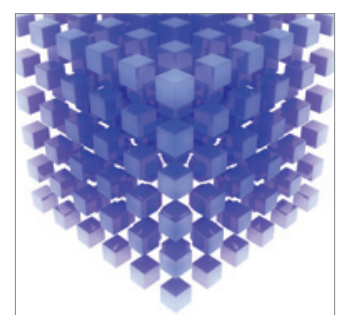

Mathematical Problems in Engineering
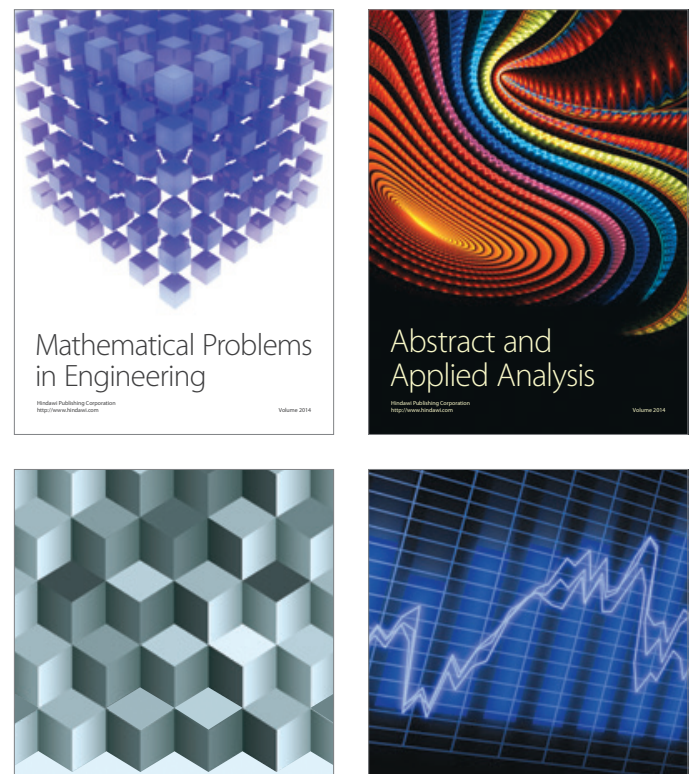

Journal of

Function Spaces

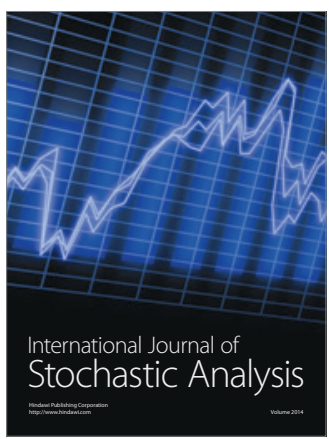

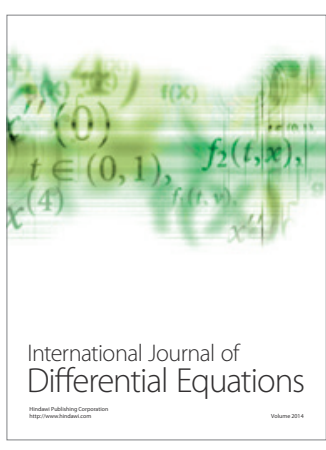
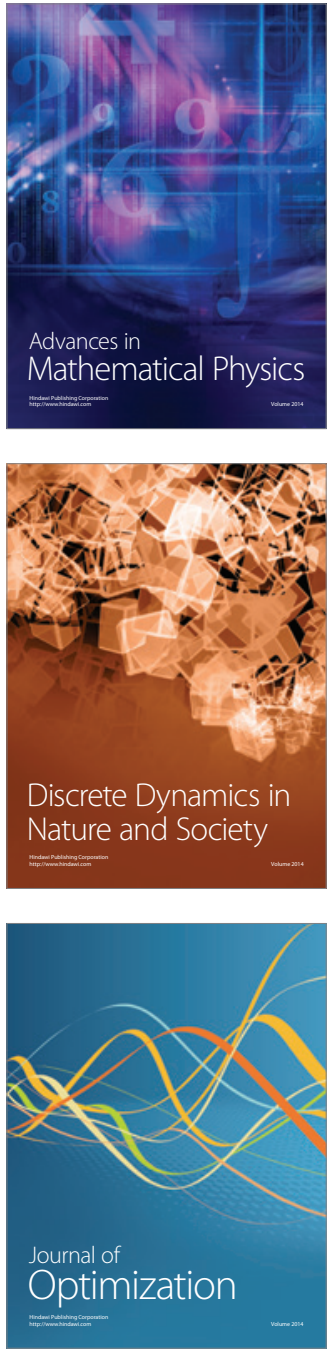